\begin{tabular}{|c|c|c|}
\hline & 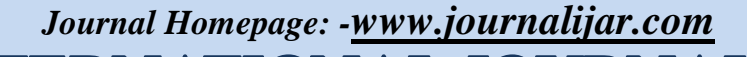 & $\begin{array}{l}\text { INTERNATIONAL JOURNAL OF } \\
\text { ADVANCED RESEARCH (IJAR) }\end{array}$ \\
\hline 0. $2320-5407$ & $\begin{array}{l}\text { Article DOI:10.21474/IJAR01/9122 } \\
\text { DOI URL: http://dx.doi.org/10.21474/IJAR01/9122 }\end{array}$ & \\
\hline
\end{tabular}

RESEARCH ARTICLE

\title{
PLASMA MAGNESIUM STATUS IN DIABETIC PATIENT WITH RETINOPATHY.
}

\section{Wafaa Kamel Abd El-moniem ${ }^{1}$, Fawzy Megahed Khalil ${ }^{1}$, Ramy Ahmed Samy ${ }^{1}$, Ahmed Mohamed Hussein Dabour ${ }^{1}$ and Marwa Abdelshafy ${ }^{2}$.}

1. Department of internal medicine,Faculty of medicine, Benha University, Egypt.

2. Department of Ophthalmology, Faculty of medicine ,Benha University, Egypt.

\section{Manuscript Info}

Manuscript History

Received: 24 March 2019

Final Accepted: 26 April 2019

Published: May 2019

\begin{abstract}
Background: Hypomagnesaemia has been reported to occur with increased frequency in patients with type 2 diabetes mellitus; it is frequently overlooked and undertreated. Hypomagnesemia has also been associated with diabetic retinopathy. Aim of the work: : The present study was conducted with an objective to evaluate the plasma magnesium in type 2 Diabetes mellitus cases. The present study also attempts to evaluate the possible relationship between diabetic retinopathy and plasma magnesium levels. Patients and methods:In this study 50 type 2 diabetic patients with age group of 30 to 70 years were included and divided into 3 groups.group I included diabetic patients with PDR,group II included diabetic patients with NPDR and group III included diabetic patients without retinopathy.all cases were subjected to estimate biochemical parameters in form of RBS,plasma magnesium level ,HbAlc and kidney function tests ,plus fundus examination. In this study we exclude patients with renal failure,patients with acute myocardial infarction in last six months,patients on diuretics or on magnesium supplementation or magnesium containing antacid ,mala absorption syndrome,chronic diarrhea and patients with history of alchol abuse. Results: The comparative study consists of 9 diabetic patient with proliferative diabetic retinopathy( group I), 21 diabetic patient with non proliferative diabetic retinopathy (groupII) and 20 diabetic patient with out diabetic retinopathy(group III). The average range of plasma Magnesium level among 3 groups was $1.36 \pm 0.26$, $1.62 \pm 0.26$ and $1.86 \pm 0.20$ respectively, There is significant difference among 3 group $(\mathrm{P}<0.05)$, low level of plasma magnesium with group I (proliferative diabetic retinopathy) and high level with group III(with out retinopathy).Conclusion: The serum magnesium levels were significantly lower in patients with diabetic retinopathy compared to diabetics without complications.
\end{abstract}

Copy Right, IJAR, 2019,. All rights reserved.

\section{Introduction:-}

Diabetes Mellitus is a metabolic and endocrine disorder characterized by both insulin deficiency and insulin resistance. Most of the cases are diagnosed as Type 2 diabetes. Type 2 diabetes has become a leading cause of

Corresponding Author:-Wafaa Kamel Abd El-moniem.

Address:-Department of internal medicine,Faculty of medicine , Benha University, Egypt. 
morbidity and mortality across the world. The incidence of diabetes is increasing globally and in India. W.H.O has declared India as the global capital of diabetes. In 1997 WHO estimate of the prevalence of the diabetes in adults showed an expected rise of > 120\% from 135 million in 1995 to 300 million in 2025 (1)

India leads in the world with its largest number of diabetes subjects as compared with any other given country, It has been estimated that presently 19.4 million individuals are affected by diabetes and these numbers are expected to increase to 57.2 million by the year 2025 (1/6th of world total), Diabetes complications are likely because of its metabolic changes. Chronic complications include majorly retinopathy, nephropathy, and neuropathy (2) .

Mineral ions play specific roles in our body. One of the important mineral cation is magnesium $(\mathrm{Mg})$, which is a cofactor in glucose transporting mechanism of the cell membrane of nearly or more than cellular enzymatic systems, Magnesium is the second most common intracellular cation, Many studies have been shown reduced magnesium concentrations in diabetic adults ,Intracellular magnesium is having an important role in insulin action regulation, insulin-mediated glucose uptake, and vascular tone. In diabetic patients, reduced intracellular $\mathrm{Mg}$ concentrations results in abnormal tyrosine-kinase activity, post receptorial impairment in insulin action, and insulin resistance worsening. (3) .

Magnesium $(\mathrm{Mg}$ ) deficiency can be rarely seen in healthy persons, but has been reported in $47 \%$ of hospitalized patients . Not only Patients with diabetes have lower serum $\mathrm{Mg}$ levels compared with their counterparts without diabetes, but also the serum Mg levels among the cohort with diabetes had an inverse correlation with the retinopathy, Magnesium depletion has been linked to development of diabetic retinopathy .(4).

Hypomagnesaemia, defined by low serum $\mathrm{Mg}$ concentrations, has been reported to occur in13.5to $47.7 \%$ of regular visit patients with type 2 diabetes while in non-diabetes persons it is reported 2.5 to $15 \%(\mathbf{5})$.

\section{Aim of the work}

To assess plasma magnesium level in relation to all stages of diabetic retinopathy.

\section{Patients and Methods:-}

Randomly chosen 50 Type 2 diabetic patients, and a descriptive study was be done to them during attending diabetic clinic.

\section{Method Of Collection Of Data:}

In this study 50 Type 2 diabetic patients with age group of 30 to 70 years who were fit in inclusion criteria were studied.

\section{Detailed history and clinical examination and biochemical investigations were included:}

Patients age ,sex, duration of diabetes mellitus, Details regarding presenting complaints, Past history of any Other diseases, History of comorbid diseases like hypertension, Ischemic heart disease.

Family history of Diabetes and Hypertension was taken and Detailed general. physical examination was conducted and detailed systemic examination was carried out in all patients. Fundoscopic examination done in all patients .

\section{Biochemical Tests Done Among Diabetic Patients:}

1. RBS.

2. Serum magnesium Levels. 3-HbA1C.

3. Kideny function tests.

\section{Inclusion Criteria:}

All cases of Type 2 diabetes mellitus aged between 30 to 70 years attending diabetic clinic, with or without retinopathy. 


\section{Exclusion Criteria:}

1. Patients with renal failure.

2. Patients who suffered acute myocardial infarction in last six months

3. Patients on diuretics.

4. Patientsonmagnesiumsupplements/magnesiumcontaining antacids.

5. Malabsorption.

6. Chronic diarrhea.

7. Patients with history of Alcohol abuse.

For the study,Patients were divided into 3 groups according to their fundus examination:

Group I:( 9 )diabetic patients with PDR. GroupII:(21)diabetic patients with NPDR. GroupIII:(20)diabetic patients without retinopathy .

The normal serum magnesium level is ranging from $1.8 \mathrm{mg} / \mathrm{dl}$ to $2.9 \mathrm{mg}$

/dL. Serurn magnesium levels $<1.5 \mathrm{mg} / \mathrm{DL}$ is considered as low magnesium level in this study.

\section{Data management}

The clinical data were recorded on a report form. These data were tabulated and analyzed using the computer program SPSS (Statistical package for social science) version 16 to obtain:

\section{Descriptive data}

Descriptive statistics were calculated for the data in the form of:

1. Mean and standard deviation $\square \square \square \mathrm{SD} \square$.for quantitative data.

2. Frequency and distribution for qualitative data.

\section{Analytical statistics}

In the statistical comparison between the different groups, the significance of difference was tested using one of the following tests:- 1- Student's t-test:- Used to compare mean of two groups of quantitative data.

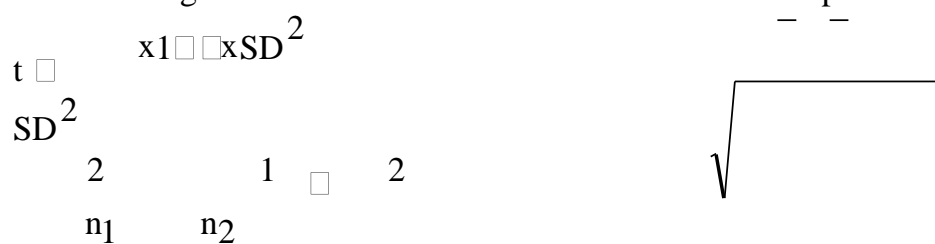

ANOVA test (F value):-Used to compare mean of more than two groups of quantitative data. Inter-group comparison of categorical data was performed by using fisher exact test (FET). orrelation coefficient:- to find relationships between variables.

A P value $<0.05$ was considered statistically significant $(*)$ while $>0.05$ statistically insignificant $\mathrm{P}$ value $<0.01$ was considered highly significant $(* *)$ in all analyses.

Results

The comparative study consists of 9 diabetic patient with proliferative diabetic retinopathy( group I), 21 diabetic patient with non proliferative diabetic retinopathy (groupII) and 20 diabetic patient with out diabetic retinopathy(group III).We considered to investigate the pattern of serum magnesium in the mentioned grougs.In table (1) below, illustrate the average age of subjects in the 3 groups in as per mentioned order was $53.33 \pm 11.18$, $59.24 \pm 6.92$ and $55.6 \pm 11.89$ respectively.Among all the groups the gender distribution was $44.4 \%$ to $55.6 \%$,28.6 $\%$ to $71.4 \%$ and $40 \%$ to $60 \%$ female to male respectively.

Table 1:-Demographic features of studied groups .

\begin{tabular}{|l|r|r|r|r|c|}
\hline & Group I (9) & Group II & Group III & Test & P value \\
& & $(21)$ & $(20)$ & & \\
\hline Age mean \pm SD & $53.33 \pm 11.18$ & $59.24 \pm 6.92$ & $55.6 \pm 11.89$ & ${ }^{\wedge} 1.32$ & 0.276 \\
\hline Sex N\&\% & $4(44.4)$ & $6(28.6)$ & $8(40.0)$ & $\# 1.02$ & 0.636 \\
Male Female & $5(55.6)$ & $15(71.4)$ & $12(60.0)$ & & \\
\hline
\end{tabular}


Table 2:-Comparison between the studied groups regarding duration, RBS and HbA1c

\begin{tabular}{|l|c|c|c|c|c|}
\hline & Group I (9) & Group II (21) & $\begin{array}{l}\text { Group III } \\
(20)\end{array}$ & Test & P value \\
\hline $\begin{array}{l}\text { Duration mean } \\
\pm \text { SD }\end{array}$ & $11.89 \pm 7.69$ & $10.69 \pm 5.75$ & $6.62 \pm 5.6^{\mathrm{ab}}$ & $\wedge 3.32$ & $0.045^{*}$ \\
\hline $\begin{array}{l}\text { RBS mean } \\
\pm \text { SD }\end{array}$ & $378.22 \pm 84.76$ & $257.24 \pm 70.88^{\mathrm{a}}$ & $189.45 \pm 21.4^{\mathrm{ab}}$ & $\wedge 31.34$ & $0.001^{* *}$ \\
\hline $\begin{array}{l}\mathrm{HbA1c} \text { mean } \\
\pm \text { SD }\end{array}$ & $9.66 \pm 1.19$ & $8.12 \pm 0.71^{\mathrm{a}}$ & $7.2 \pm 0.65^{\mathrm{ab}}$ & $\wedge 30.28$ & $0.001^{* *}$ \\
\hline
\end{tabular}

The average range of duration among 3 groups was $11.89 \pm 7.69$ , $10.69 \pm 5.75$ and $6.62 \pm 5.6$ respectively, There is significant difference among 3 group $(\mathrm{P}<0.05)$,long duration with groupI.

The average range of RBS among 3 groups was $378.22 \pm 84.76,257.24 \pm 70.88$ and $189.45 \pm 21.4$ respectively ,There is significant difference among 3 group $(\mathrm{P}<0.05)$, high level of RBS with group I.

The average range of HbA1c mong 3 groups was $9.66 \pm 1.19,8.12 \pm 0.71$ and $7.2 \pm 0.65$ respectively , There is significant difference among 3 group $(\mathrm{P}<0.05)$, high level of HbA1c with group $\mathrm{I}$.

Figure 1:-Comparison between the studied groups in type 2 diabetes mellitus regarding mean duration.

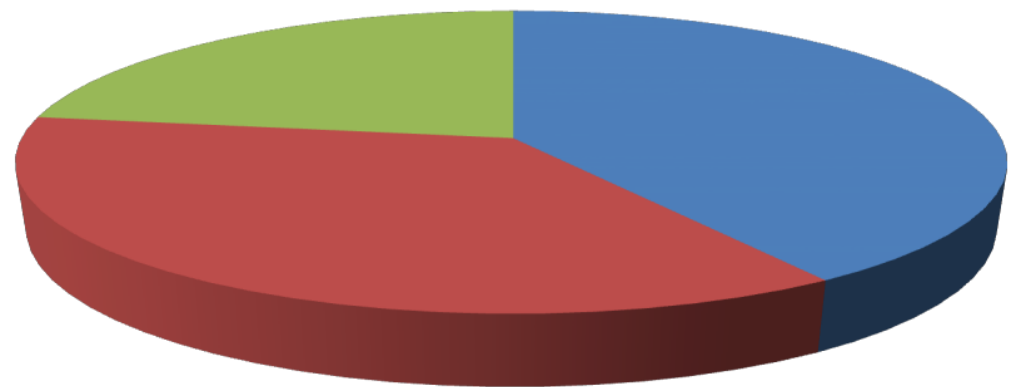



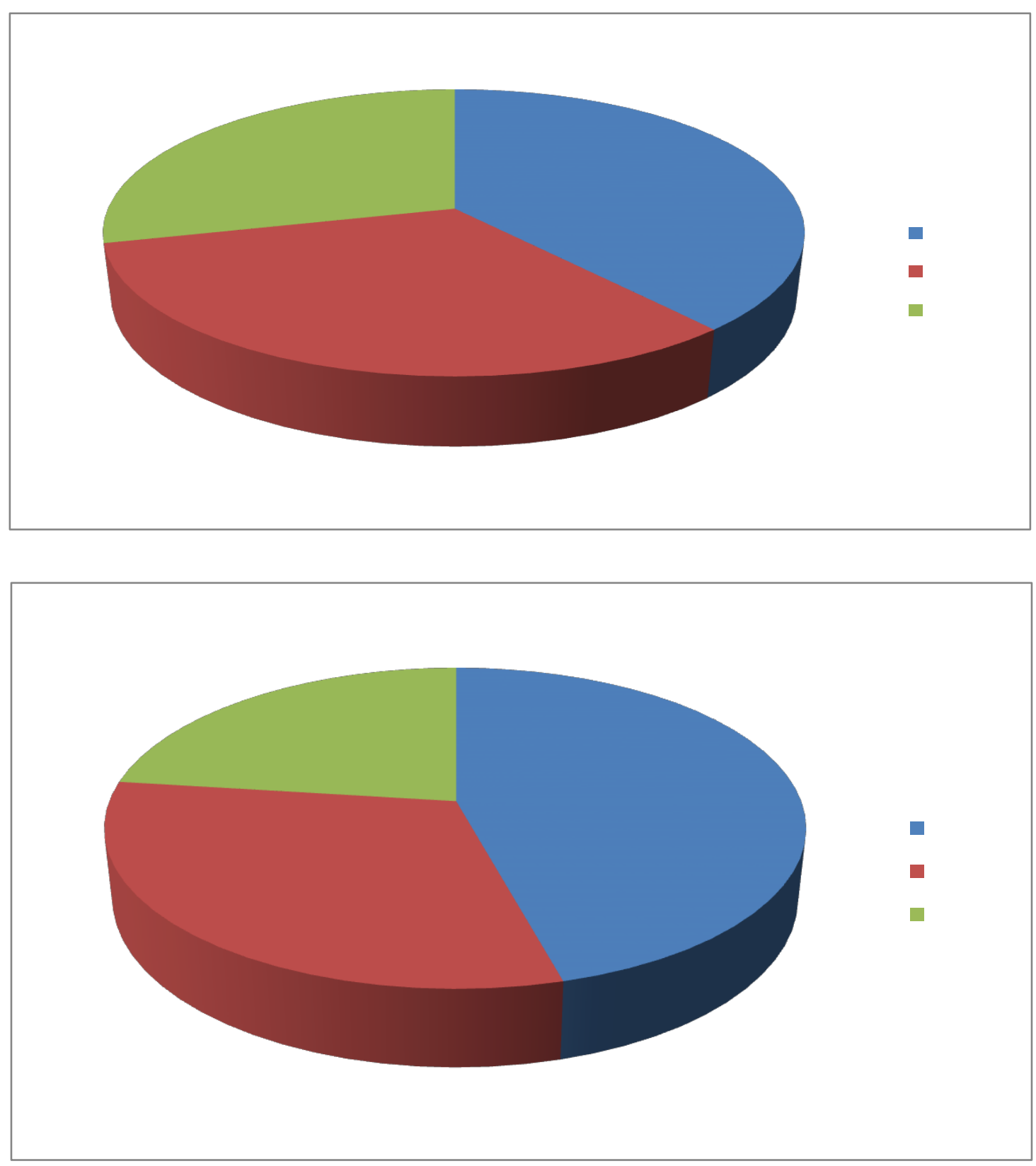


$$
1^{\text {st }} \text { Qtr =GroupI } \quad 2^{\text {nd }} \text { Qtr=Group II } \quad 3^{\text {rd }} \text { Qtr =GroupIII }
$$

Table3:- Comparison between the studied groups regarding Mg level

\begin{tabular}{|ll|c|r|r|r|c|}
\hline & Group I (9) & Group II & Group III & Test & P value \\
\hline $\mathrm{Mg}$ & mean $\pm \mathrm{SD}$ & $1.36 \pm 0.26$ & $1.62 \pm 0.26^{\mathrm{a}}$ & $1.86 \pm 0.20^{\mathrm{ab}}$ & $\wedge 15.16$ & $0.001^{* *}$ \\
\hline
\end{tabular}

The average range of serum Magnesium level among 3 groups was $1.36 \pm 0.26,1.62 \pm 0.26$ and $1.86 \pm 0.20$ respectively, There is significant difference among 3 group $(\mathrm{P}<0.05)$, low level of serum magnesium with group I (proliferative diabetic retinopathy) and high level with group III(with out retinopathy).

Table 4:-Comparison between the studied groups regarding clinical evident neuropathy

\begin{tabular}{|l|l|l|l|l|l|}
\hline & Group I (9) & Group II (21) & Group III (20) & Test & P value \\
\cline { 1 - 4 } Clinical evident & & & & & \\
\cline { 1 - 5 } neuropathy & $9(100) \%$ & $19(90.5) \%$ & $9(45.0) \%$ & \multirow{2}{*}{$\# 13.73$} & \multirow{2}{*}{$0.001^{* *}$} \\
\cline { 1 - 4 } Yes & $0(0.0) \%$ & $2(9.5) \%$ & $11(55.0) \%$ & & \\
\hline
\end{tabular}

The percentage of clinical evident neuropathy among 3 groups was $100 \%, 90.5 \%$ and $45 \%$ respectively.

Figure 4:- Comparison between the studied groups regarding mean plasma $\mathrm{Mg}$ level.

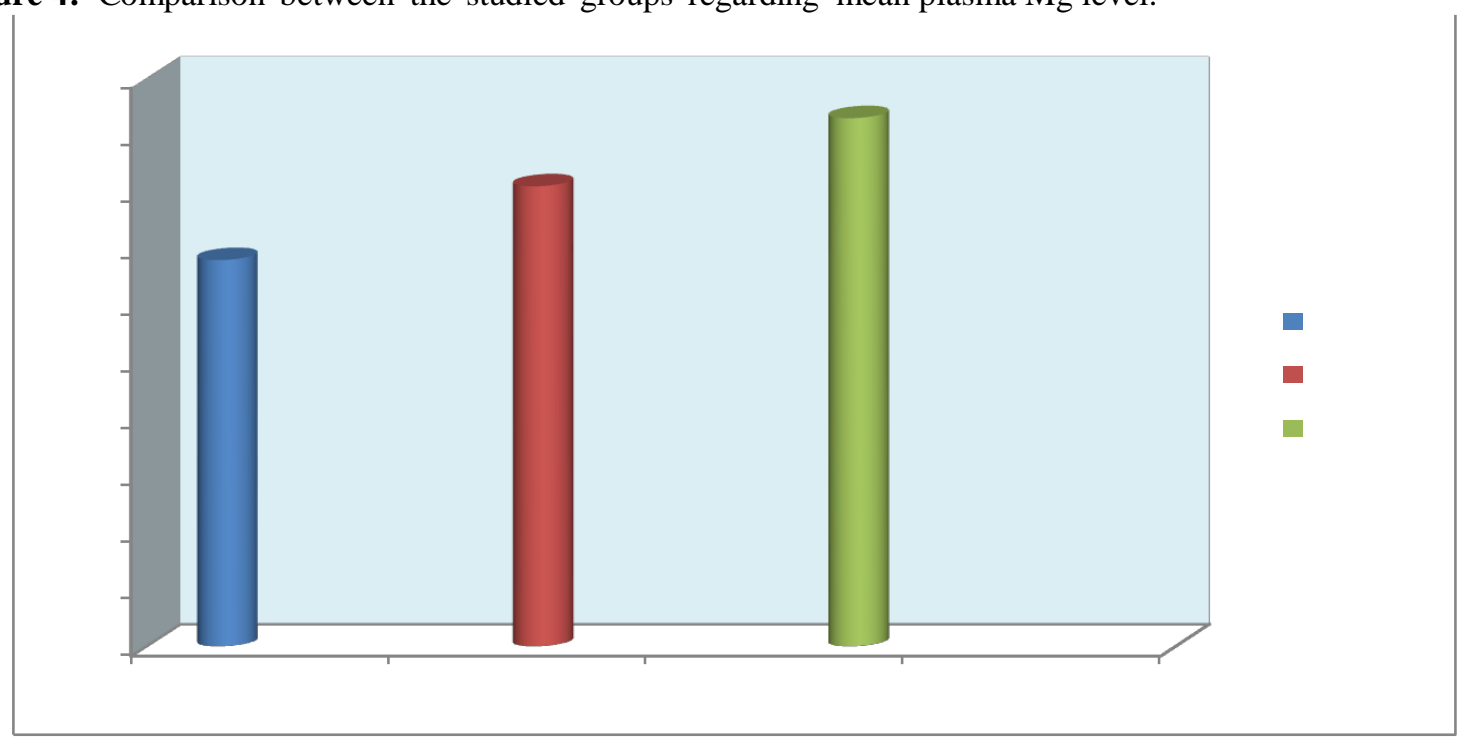

$\begin{array}{lll}\text { Category } 1 & \text { Category } 2 & \text { Category } 3\end{array}$
Category $1=$ GroupI
Category 2=GroupII
Category 3=GroupIII 

$1^{\text {st }}$ Qtr $=$ GroupI
$2^{\text {nd }}$ Qtr=Group II
$3^{\text {rd }}$ Qtr $=$ GroupIII

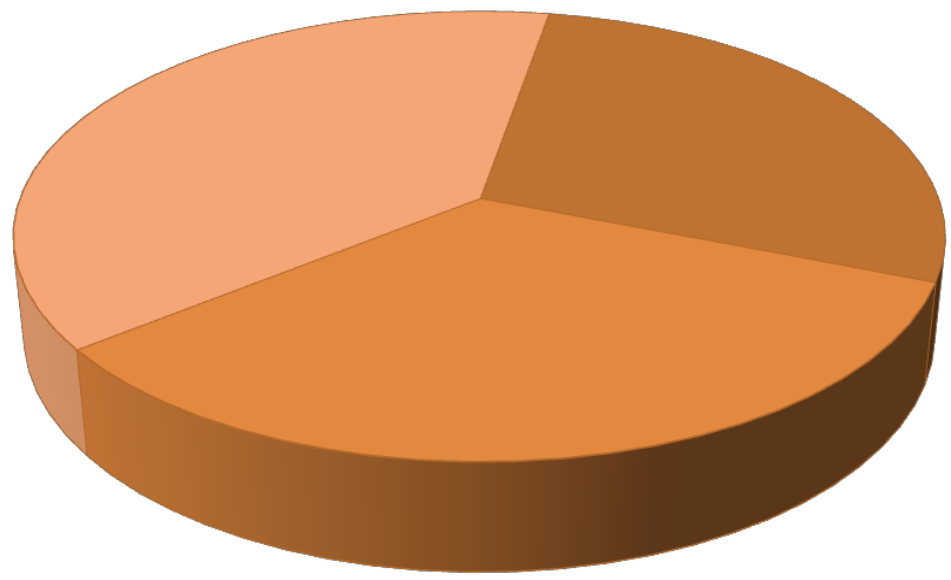

Category $1 \quad$ Category $2 \quad$ Category 3

Figure 5:-Comparison between the studied groups regarding clinical evident neuropathy.

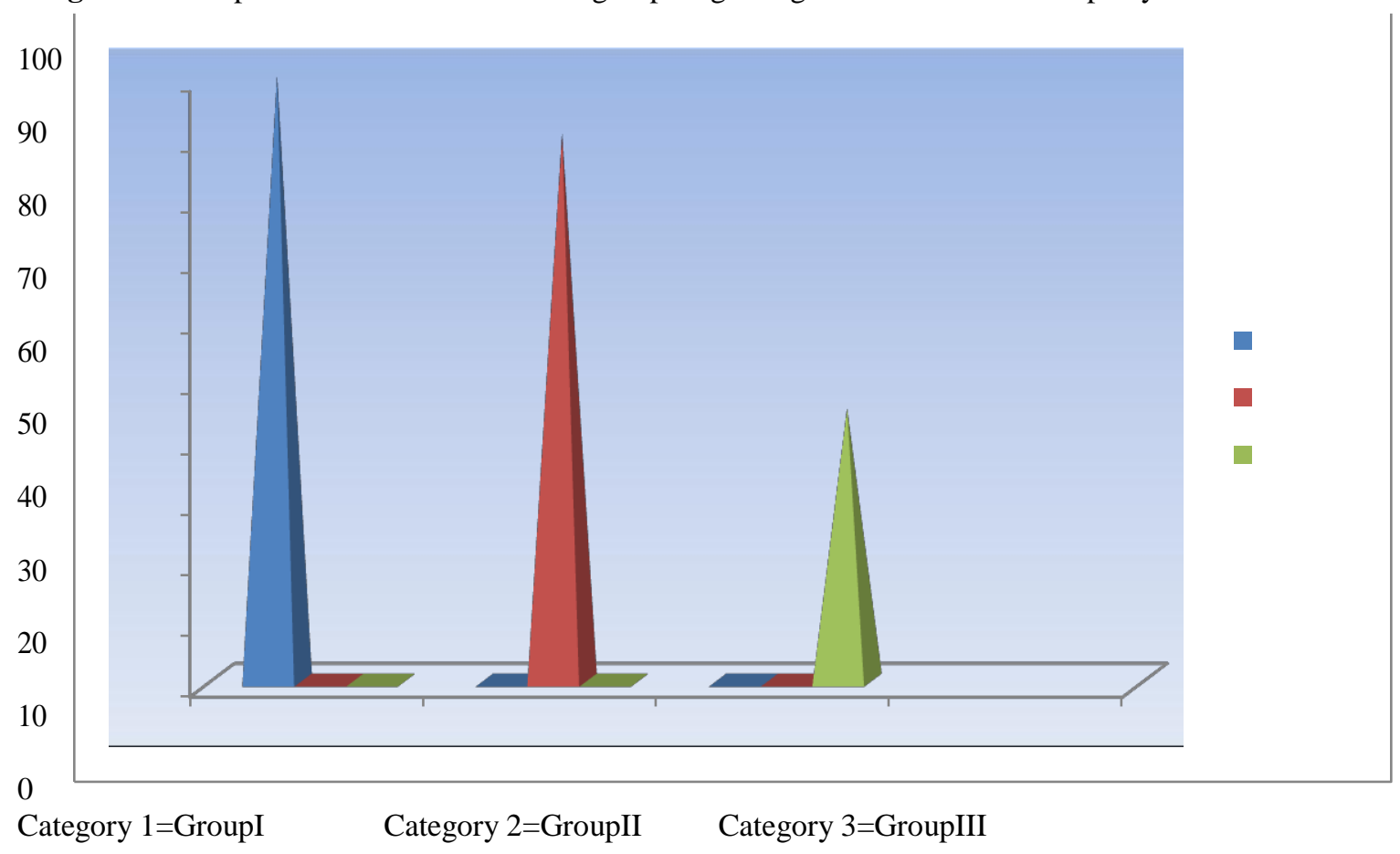

Table 5:-Comparison between the studied groups

\begin{tabular}{|l|r|r|r|r|r|}
\hline & Group I (9) & Group II (21) & Group III (20) & Test & P value \\
\hline Age & $53.33 \pm 11.18$ & $59.24 \pm 6.92$ & $55.6 \pm 11.89$ & $\wedge 1.32$ & 0.276 \\
$\begin{array}{l}\text { ean } \\
\pm \text { SD }\end{array}$ & & & & & \\
\hline Sex & & & & & \\
\cline { 1 - 4 } N\&\% & & & & & \\
\hline
\end{tabular}




\begin{tabular}{|c|c|c|c|c|c|}
\hline & $4(44.4)$ & $6(28.6)$ & $8(40.0)$ & \multirow[t]{3}{*}{$\# 1.02$} & \multirow[t]{3}{*}{0.636} \\
\hline Male & \multirow[t]{2}{*}{$5(55.6)$} & \multirow{2}{*}{$15(71.4)$} & \multirow[t]{2}{*}{$12(60.0)$} & & \\
\hline Female & & & & & \\
\hline $\begin{array}{l}\text { Duration } \\
\text { mean } \pm \mathrm{SD}\end{array}$ & $11.89 \pm 7.69$ & $10.69 \pm 5.75$ & $6.62 \pm 5.6^{\mathrm{ab}}$ & $\wedge 3.32$ & $0.045^{*}$ \\
\hline $\begin{array}{l}\text { RBS } \\
\text { mean } \\
\pm \mathrm{SD} \\
\end{array}$ & $378.22 \pm 84.76$ & $257.24 \pm 70.88^{\mathrm{a}}$ & $189.45 \pm 21.4^{\mathrm{ab}}$ & $\wedge 31.34$ & $0.001^{* *}$ \\
\hline $\begin{array}{l}\text { HbA1c } \\
\text { mean } \pm \text { SD }\end{array}$ & $9.66 \pm 1.19$ & $8.12 \pm 0.71^{\mathrm{a}}$ & $7.2 \pm 0.65^{\mathrm{ab}}$ & $\wedge 30.28$ & $0.001^{* *}$ \\
\hline $\begin{array}{ll}\mathrm{Mg} & \\
& \\
\mathrm{n} & \\
\pm \mathrm{SD} & \\
\end{array}$ & $1.36 \pm 0.26$ & $1.62 \pm 0.26^{\mathrm{a}}$ & $1.86 \pm 0.20^{\mathrm{ab}}$ & $\wedge 15.16$ & $0.001^{* *}$ \\
\hline Clinical & \multirow{3}{*}{$\frac{9(100)}{0(0.0)}$} & \multirow{3}{*}{$\frac{19(90.5)}{2(9.5)}$} & \multirow{3}{*}{$\begin{array}{r}9(45.0) \\
11(55.0)\end{array}$} & \multirow{3}{*}{$\# 13.73$} & \multirow{3}{*}{$0.001 * *$} \\
\hline Evident & & & & & \\
\hline $\begin{array}{l}\text { Neuropathy } \\
\text { Yes } \\
\text { No }\end{array}$ & & & & & \\
\hline
\end{tabular}

a: Significant difference $(\mathrm{p}<0.05)$ compared with groupI. b: Significant difference $(\mathrm{p}<0.05)$ compared with group II. $\wedge=$ ANOVA test

\#= Fisher exact test

Figure 6:-Comparison between the studied groups .

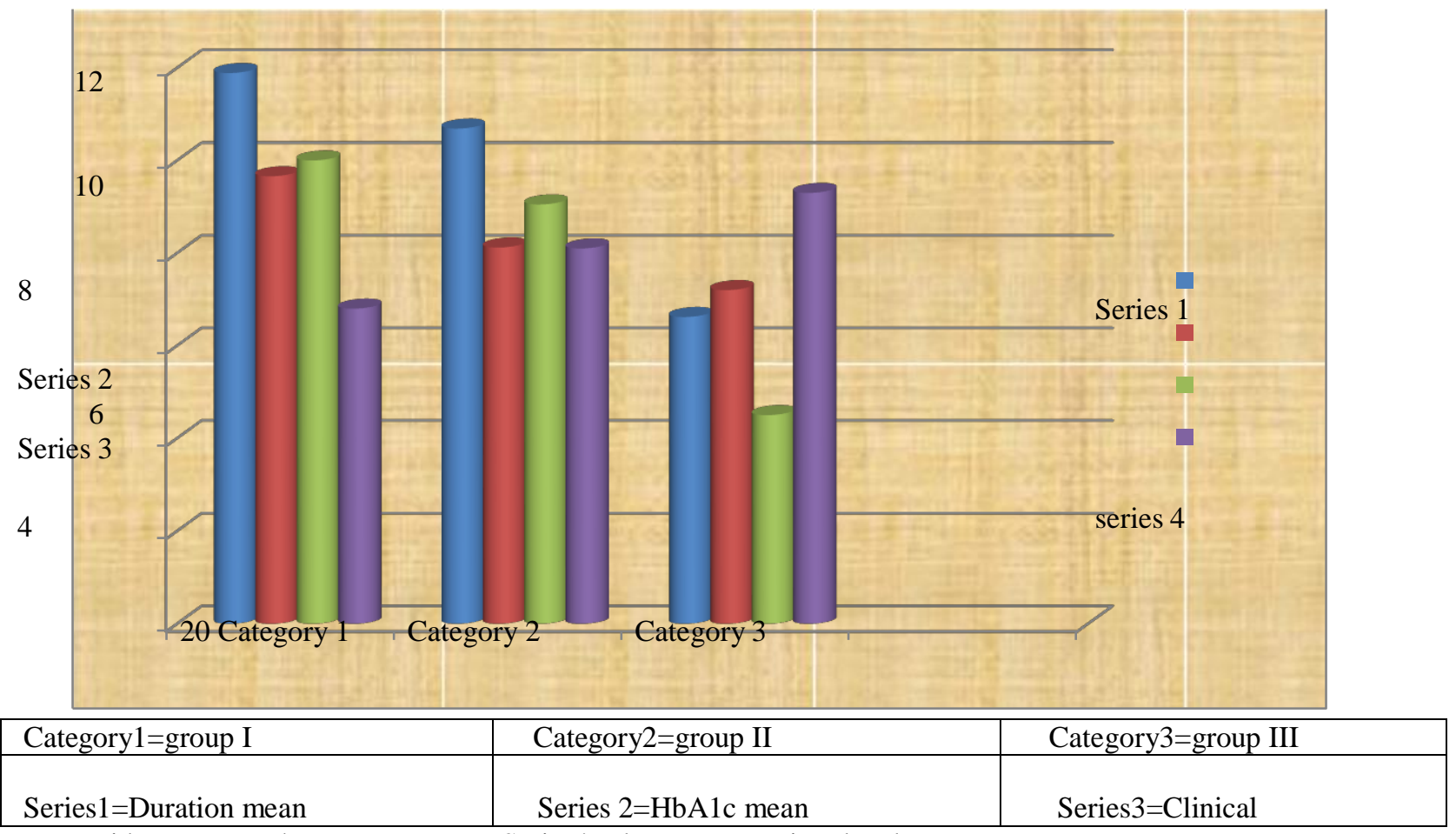
evident neuropathy

Series4=Plasma magnesium level mean

\section{Discussion:-}

Magnesium $(\mathrm{Mg})$, is one of the most abundant intracellular ions with an essential role in fundamental biological reactions. Magnesium activates more than 300 enzymes in the body and is a critical cofactor of many 
enzymes in carbohydrate metabolism. Cellular magnesium deficiency can alter the activity of membrane bound sodium- potassium ATPase.(6).

Diabetes mellitus (DM), characterized by metabolic disorders related to high levels of serum glucose, is probably the most common disease associated with $\mathrm{Mg}$ depletion in intra and extra cellular compartments.(7).

Hypomagnesemia has been related, as a cause, to insulin resistance, also being a consequence of hyperglycemia, and when it is chronic, it leads to the development of macro and microvascular complications of diabetes, that worsen the deficiency of $\mathrm{Mg}$.

Hypomagnesemia, defined by low serum $\mathrm{Mg}$ concentrations, has been reported to occur in $13.5 \%$ to $47.7 \%$ of non hospitalized patients with type 2 diabetes compared with $2.5 \%$ to $15 \%$ among normal subject.(8).

In diabetes, there is a direct relationship between serum magnesium level and cellular glucose disposal that is independent of insulin secretion. This change in glucose disposal has been shown to be related to increased sensitivity of the tissues to insulin in presence of adequate magnesium levels. It is observed that low serum magnesium concentration and poor magnesium status are common in Type 2 diabetes mellitus. Preventing hypomagnesaemia in diabetes by supplementing magnesium may be helpful in increasing insulin sensitivity and delaying the development of late diabetic complications. the aim of the study is to compare the serum magnesium concentrations in patients with Type 2 diabetes to assess its impact on complications .

The current study enrolled 50 diabetic patients consulting Ophthalmology Outpatient Department. the patients were classified into 3 categories; proliferative retinopathy, non proliferative retinopathy and without retinopathy respectively. Serum magnesium, random blood glucose and glycated hemoglobin were determined. Among the 50 patients with diabetes mellitus, 9 patients had proliferative diabetic retinopathy(group I), 21 patients had non proliferative diabetic retinopathy (group II)and 20 patients without retinopathy(group III) respectively. There is a significant statistical differences (P-value <0.05) between diabetic retinopathy(group I, II) and control groups(group III) in serum magnesium, random blood glucose, glycated hemoglobin and duration of diabetes. The average range of serum Magnesium level among 3 groups was $1.36 \pm 0.26,1.62 \pm 0.26$ and $1.86 \pm 0.20$ respectively, There is significant difference among 3 group $(\mathrm{P}<0.05)$, low level of serum magnesium with group I (proliferative diabetic retinopathy) and high level with group III(with out retinopathy). Serum magnesium level decreased in patients with diabetic retinopathy with lowest level being observed in patients with advanced retinopathy and maculopathy.

The results of current study were agreed with( Mohamed Murtuza, et al): Study of serum magnesium level in diabetic retinopathy reveal that the serum magnesium levels were significantly lower in patients with diabetic retinopathy compared to diabetics without complications. 120 subjects were included in this study and divided into 3 groups. The study group consisted of 40 patients that are type 2 diabetes and retinopathy and the control groups consisted of 40 patients with type diabetes without retinopathy and 40 healthy subjects respectively. Both cases and controls were subjected to estimation of biochemical parameters.,statistically observed There is significant difference between levels of serum magnesium levels among diabetics without complications and healthy subjects. The mean serum magnesium levels among the above groups are $1.79 \pm 0.15 \mathrm{mg} / \mathrm{dl}$ and $2.25 \pm 0.16 \mathrm{mg} / \mathrm{dl}$ respectively

There is also significant difference between levels of serum magnesium levels among diabetic retinopathy patients and diabetics without complications i.e. $1.62 \pm 0.13 \mathrm{mg} / \mathrm{dl}$ and $1.79 \pm 0.15 \mathrm{mg} / \mathrm{dl}$ respectively (9).

Study of serum Magnesium levels in type 2 Diabetes Mellitus, This study demonstrated that Low Mg2+ status is common in Type 2 diabetes mellitus patients when compared to non diabetic controls. It may be prudent in clinical practice to periodically monitor plasma $\mathrm{Mg} 2+$ concentration in diabetic patients. If plasma $\mathrm{Mg} 2+$ is low, an intervention to increase dietary intake of magnesium may be beneficial. This study was done in randomly chosen 100 Type 2 diabetic patients, and 100 non diabetic age / sex matched controls age group 30 to 70 years attending diabetic clinic. All patients and controls underwent thorough clinical examination and estimation of serum magnesium, FBS, PPBS, lipid profile and urea, creatinine levels. Statistically observe that $37 \%$ of diabetic patients had low serum magnesium levels $(\mathrm{Mg} 2+$ level $<1.5 \mathrm{mg} / \mathrm{dL})$ and $9 \%$ of controls had low 
serum magnesium levels $(\mathrm{Mg} 2+\mathrm{level}<1.5 \mathrm{mg} / \mathrm{dL})$. The mean serum magnesium levels were $1.96=0.54 \mathrm{mg} / \mathrm{dL}$ and $\quad 2.375+0.449 \mathrm{mg} / \mathrm{dL}$, in diabeticsand controls respectively. There is negative co relationship between Sr.Mg Levels and hypertension and there was also found to be negative correlation between $\mathrm{Mg}$ and retinopathy. Hypomagnesaemia $(\mathrm{Mg} 2+$ Level $<1.5 \mathrm{mg} / \mathrm{dL})$ is correlating with retinopathy In this study hence there is an association between retinopathy and serum $\mathrm{Mg} 2+$ level .

The results of current study were agreed also with (Nazar, et al.,): Study of serum Magnesium and severity of Diabetic retinopathy, revealed that Serum magnesium level decreased in patients with diabetic retinopathy with lowest level being observed in patients with advanced retinopathy and maculopathy. The study enrolled 136 diabetic patients consulting Ophthalmology Outpatient Department. The ophthalmologist assigned the patients into 5 categories; background, preproliferative, proliferative, advanced and maculopathy. Serum magnesium, random blood glucose and glycated hemoglobin were determined. Among the 136 patients with diabetes mellitus, 94 patients had diabetic retinopathy and 42 had no retinopathy. There is a significant statistical differences between diabetic retinopathy and control groups in serum magnesium, random blood glucose, glycated hemoglobin and duration of diabetes. It had been found that serum magnesium remained statistically significant among the groups of patients with different stages of retinopathy. Patients with maculopathy had the lowest value for the serum magnesium level (1.35 mg/dl) (10).

The results of current study were agreed also with(Mirza Sharif ,et al.,): Statistically observed the mean serum magnesium level which was significantly low in Diabetic patients with retinopathy, when compared with controls. In their study, cases with diabetic retinopathy had serum magnesium level $(1.28+0.30)$ of much lower when compared with diabetic patients without retinopathy $(1.60+0.40)(\mathbf{1 1})$.

The results of current study were agreed also with( Ishrath Kareem, et al.,): Found that serum magnesium levels in diabetic retinopathy patients were significantly low when compared to patients without retinopathy(12).

The results of current study were agreed also with (Aradhana Sharma, et al,) :Also found that serum magnesium levels were significantly lowered in patients with diabetic retinopathy when to diabetic patients without retinopathy $(\mathbf{1 3})$.

The results of current study were agreed also with (Hatwal, et al.,) : Studied the association of hypomagnesaemia with diabetic retinopathy and observed that serum magnesium levels were significantly lower in diabetic retinopathy patients than in those patients without diabetic retinopathy. Their study also found significantly low serum magnesium levels in diabetic patients with proliferative and non-proliferative retinopathy than those patients without retinopathy $(\mathbf{1 4})$.

The results of current study agreed also with (Valk ,et al.,): Who observed a significant association between plasma Mg concentration and development of background retinopathy but did not state association with the severity of retinopathy. Consequently hypomagnesemia seem to be as a possible risk factor in the development and progress of diabetic retinopathy $(\mathbf{1 5})$.

The results of the present study showed that there were significant differences in the level of serum magnesium among different stages of retinopathy. These differences correlate negatively with advancing stages of retinopathy i.e. the more advanced the stage of retinopathy, the lower is the serum magnesium concentration. Low Mg levels may also lead to induction of pro- inflammatory and pro-fibrogenic response and to reduction of protective enzymes against oxidative stress. Moreover, because $\mathrm{Mg}$ is crucial in DNA synthesis and repair. it is possible that $\mathrm{Mg}$ deficiency may interfere with normal cell growth and regulation of apoptosis. We, therefore, conclude that serum magnesium level decreased in patients with diabetic retinopathy with lowest level being observed in patients with advanced retinopathy and maculopathy.

\section{Conclusion:-}

Hypomagnesaemia is likely among patients with type 2 diabetes mellitus. Long term complications especially retinopathy may have hypomagnesemia as a contributing factor. Because $\mathrm{Mg} 2+$ depletion reduces insulin sensitivity and may increase risk of secondary complications, Hence it is prudent that serum magnesium levels are carefully monitored in diabetic patients. 


\section{References:-}

1. King H,Aubert RE,Herman WH ,et al., (1998): Global burden of diabetes,1995-2025.Diabetes-care;21:141431.

2. American Diabetes Association (2014): Diagnosis and classification of diabetes mellitus .Diabetes care;(suppl. 1):S81-S90 .

3. Maltezos E,Papazoglou D, Exiara T, et al., (2004): Serum magnesium levels in non diabetic offspring of patients with type 2 diabetes mellitus. Diabetes Nutr Metab;17:12-6.

4. Whang R,Ryder KW(1990):Frequency of hypomagnesemia.JAMA; 263:306364

5. Dasgupta A, Sarma D, Saikia K U(2012): Hypomagnesemia in type 2 diabetes mellitus, Indian J Endocrinol Metab. ;16(6):1000-3.

6. Grofton G, Borter (1992): The role of magnesium in diabetes mellitus. J Diabetes complications ;6;143-149.

7. 7-Delva P, Degan M, Pastori C, et al., (2002): Glucose- induced alterations of intracellular ionized magnesium in human lymphocytes.

8. Walti MK, Zimmermann MB, Spinas GA, et al., (2003): Low plasma magnesium in type 2 diabetes.Diabetes care ;133:346-355.

9. Mohamed Murtuza Kauser, Asfia Afreen, Kasi Jagadeesh M(2014):Study of Serum Magnesium Levels in Diabetic Retinopathy ,Journal of Research in Medical and Dental Science eISSN No. 2347-2367 pISSN No. 2347-2545

10. Nazar S.Hadad,Salah Zuhair (2010),serum magnesium and severity of diabetic retinopathy.The medical journal of Basrah University,vol 28,No.1

11. Baig M,Ali M.Study of serum magnesium in diabetic

12. retinopathy.Inj J Biol MedRes2012;3(4):2480-2482.

13. Kareem I,Jaweed SA,et al., (2004): Study of magnesium, glycosylated hemoglobin and lipid profile in diabetic retinopathy.Indial journal;19(2):124-7.

14. Sharma A, Dabla S , Agarwal RP et al., (2007): Serum magnesium; An early predictor of course and complications ofdiabetes mellitus. Med Assoc ;105:16-20.

15. Hatwal A ${ }^{1}$, Gujral AS, Bhatia RP, Agrawal JK, Bajpai HS(1989).

16. ASSOCIATION OF HYPOMAGNESEMIA WITH DIABETIC RETINOPATHY.

17. Acta Ophthalmol (Copenh). 1989 Dec;67(6):714-6.

18. Valk HW, Hardus PLLJ, Van Rijn ,et al., (1999): Plasma magnesium concentration and progression of retinopathy.Diabetes care ;22:864-865 . 